\title{
Inaccuracies of Hemoglobin A1c in Liver Cirrhosis: A Case Report
}

\author{
Mathew Clarke ${ }^{\mathrm{a}}$, Jamila Benmoussa ${ }^{\mathrm{a}}$, Amulya Penmetsa ${ }^{\mathrm{a}, \mathrm{b}}$, Philip Otterbeck ${ }^{\mathrm{a}}$, \\ Farhang Ebrahimi ${ }^{\mathrm{a}}$, Jay Nfonoyim ${ }^{\mathrm{a}}$
}

\begin{abstract}
Hemoglobin A1c (HbAlc) is the gold standard for the measurement of long-range glycemic control in patients with diabetes mellitus type 2 (T2DM). In a rare subset of patients, this measurement may not be reliable. Inaccuracies of $\mathrm{HbAlc}$ in liver cirrhosis are rare, but documented. The objective of this study was to increase awareness about low $\mathrm{HbA} 1 \mathrm{c}$ in liver cirrhosis and discuss alternative biomarkers that can be used to measure glycemic control. We present the case of a 61-year-old Caucasian female, with history of hepatitis $\mathrm{C}$ and uncontrolled T2DM, who was admitted for evaluation of compensated liver cirrhosis. She was found to have blood glucoses greater than $500 \mathrm{mg} /$ $\mathrm{dL}$; however, her HbA1c was measured at $5.5 \%$. Ultrasound of the abdomen showed liver cirrhosis, ascites, and splenomegaly. Blood work revealed acute kidney injury, anemia of chronic disease, normal albumin level, and low HbA1c. Fructosamine and glycated albumin were high, indicating a hyperglycemic status during the last 3 weeks. $\mathrm{HbAlc}$ can be falsely low in liver cirrhosis, and can give a false assumption about control of the diabetic disease process. In this case, other biomarkers can be used to monitor glycemic control; by far frequent finger stick monitoring is the best method.
\end{abstract}

Keywords: Low HbA1c; Glucose monitoring; Liver cirrhosis; Fructosamine; Glycated albumin

\section{Introduction}

For decades, hemoglobin A1c (HbA1c) has been the standard measure of long-range glycemic control in patients with diabetes mellitus type 2 (T2DM) even with comorbid liver cirrhosis. However, there are subsets of patients in whom there will be discordance between $\mathrm{HbAlc}$ and blood glucose measure-

Manuscript accepted for publication February 17, 2016

aDepartment of Internal Medicine, Richmond University Medical Center, Staten Island, NY, USA

${ }^{b}$ Corresponding Author: Amulya Penmetsa, Department of Internal Medicine, Richmond University Medical Center, 355 Bard Avenue, Staten Island, NY 10310, USA. Email: amulya.penmetsa@gmail.com

doi: http://dx.doi.org/10.14740/jem326w ments, rendering it less useful in determining a patient's glycemic status. We present a case of woman with uncontrolled T2DM, acute kidney injury, and liver cirrhosis and discuss the challenges of assessing this patient's glycemic control in view of the discordance between the patient's $\mathrm{HbAlc}$ and blood glucose measurements.

\section{Case Report}

A 61-year-old Caucasian woman, with history of hepatitis $\mathrm{C}$, uncontrolled T2DM, and hypothyroidism presented with shortness of breath and increasing abdominal girth. Home medications included metformin, levothyroxine, and docusate. On physical examination, the patient had pallor, non-icteric sclerae, and poor dentition. Examination of the abdomen revealed a grossly distended abdomen with a positive fluid wave and a protruding, yet reducible umbilical hernia. Laboratory work on admission showed blood glucose of $568 \mathrm{mg} /$ $\mathrm{dL}$, white blood cell count of $5.5 \times 10^{9} / \mathrm{L}$, hemoglobin of 11.5 $\mathrm{mg} / \mathrm{dL}$, hematocrit of $36.5 \%$, MCV of $98.8 \mathrm{fL}$, platelets of $104,000 / \mu \mathrm{L}$, prothrombin time of $12.1 \mathrm{~s}$, partial thromboplastin time of $26.9 \mathrm{~s}$, and international normalized ratio of 1.13. Chemistry panel showed sodium of $132 \mathrm{mmol} / \mathrm{L}$, potassium of $5.6 \mathrm{mmol} / \mathrm{l}$, creatinine of $1.6 \mathrm{mg} / \mathrm{dL}$, blood urea nitrogen of $58 \mathrm{mg} / \mathrm{dL}$, and a glomerular filtration rate of $32.7 \mathrm{~mL} / \mathrm{h}$. Liver function tests revealed total bilirubin of $0.7 \mathrm{mg} / \mathrm{dL}$, alanine aminotransferase of 74 units/L, aspartate aminotransferase of 98 units/L, alkaline phosphatase of $621 \mathrm{IU} / \mathrm{L}$, haptoglobin of $100 \mathrm{mg} / \mathrm{dL}$, lactate dehydrogenase of $220 \mathrm{IU} / \mathrm{L}$, total protein of $7.3 \mathrm{~g} / \mathrm{dL}$, and albumin of $3.2 \mathrm{~g} / \mathrm{dL}$. Iron studies showed iron level of $64 \mathrm{~g} / \mathrm{dL}$, iron-binding capacity of $212 \mathrm{~g} / \mathrm{dL}$, transferrin saturation of $30.1 \%$, and ferritin level of $661.7 \mathrm{ng} / \mathrm{mL}$. Metformin was stopped and an insulin regimen of basal glargine and pre-meal aspart was initiated. Despite medical management finger stick readings remained grossly uncontrolled (Table 1).

$\mathrm{HbAl} \mathrm{c}$ was measured and found to be $5.5 \%$. This finding was contrast to a previously measured $\mathrm{HbAlc} 1$ year prior to admission that was $13.7 \%$ (Table 2).

Possible etiologies that would explain this laboratory "mismatch", like lab error, hemoglobinopathies or hemolytic anemia, were excluded. An abdominal ultrasound showed surface nodularity in the liver consistent with cirrhosis, ascites 
Table 1. Daily Finger Stick Log (mg/dL)

\begin{tabular}{llllll}
\hline Time & Day 1 & Day 2 & Day 3 & Day 4 & Day 5 \\
\hline 6 am & 459 & 263 & 161 & 410 & 94 \\
$12 \mathrm{pm}$ & 369 & 308 & 246 & 226 & 187 \\
$5 \mathrm{pm}$ & 298 & 250 & 189 & 217 & 114 \\
Bedtime & 458 & 170 & 246 & 364 & 123 \\
\hline
\end{tabular}

and splenomegaly.

HbAlc can be calculated by using average glucose (eAG) from seven consecutive finger stick readings within 2 days (calculation $28.7 \times \mathrm{HbA1c}-46.7=\mathrm{eAG}$ ) [1]. In our patient's case, this value was found to be $12.08 \%$. Given the discrepancy between finger stick blood glucose, calculated $\mathrm{HbAlc}$ and $\mathrm{HbA} 1 \mathrm{c}$ measured in the laboratory, other markers were considered to monitor glycemic control, mainly fructosamine 415 $\mu \mathrm{mol}$ (normal: 200 - $285 \mu \mathrm{mol}$ ) and glycated albumin $4.7 \%$ (normal: $0.8-1.4 \%$ ).

After dosing adjustments were made to the patient insulin regime, the patient's blood glucose became controlled.

\section{Discussion}

$\mathrm{HbAlc}$ has been widely accepted as the best long-range indicator of glycemic control in a diabetic patient. It is created when glucose binds to $\mathrm{N}$-terminal valine of normal adult $\mathrm{HbA}$. It is a representation of the fraction of hemoglobin proteins bound to glucose. The initial reference range of $\mathrm{HbAlc}$ was created based on a normal red blood cell lifespan. Changes in the availability of glucose, glycation rate, and red blood cell lifespan can alter $\mathrm{HbAlc}$ values [2]. False $\mathrm{HbA1c}$ values can be expected in patients with diseases that affect one or more of these factors. These include hemolytic anemia, hemoglobinopathies, renal failure, and liver cirrhosis [2-4]. Multiple factors contribute to shortened red blood cell survival and changes in HbAlc seen in liver cirrhosis like anemia of chronic disease, iron, folate or vitamin B12 deficiency anemia (frequent in case of alcoholism and malnutrition), low albumin, gastrointestinal bleed, or hypersplenism. Occasionally, autoimmune hepatitis can be associated with hemolytic anemia; however, hypersplenism causes sequestration of red blood cells and is the most frequent cause $[3,4]$. In our patient, with T2DM and liver cirrhosis, splenomegaly, anemia of chronic disease, a low HbAlc did not indicate optimal glycemic control. In such situations, other parameters have emerged as having clinical significance in patients with diabetes and liver cirrhosis. Specifically, fructosamine and glycated albumin (GA) have been considered, as well as an overall measure known as chronic liver disease-HbA1c (CLD-HbA1c). CLD-HbA1c is defined by the formula- $(\mathrm{HbA} 1 \mathrm{c}+\mathrm{GA} / 3) / 2$, where GA represents the portion of albumin that is glycated relative to the total albumin. It has been found to relate well to $\mathrm{HbA} 1 \mathrm{c}$ calculated using average glucose [1] while simultaneously correcting for the confounding factor of cirrhosis (albumin and hemoglobin turnover). However, patients with renal disease were not accounted for in this study [5]. Since our patient was
Table 2. Hemoglobin A1C

\begin{tabular}{ll}
\hline Year & HbA1c \\
\hline 2014 & $13.7 \%$ \\
2015 & $5.5 \%$ \\
\hline
\end{tabular}

found to have acute kidney injury on admission, this measure alone would not be sufficient. Fructosamine is created when ketamines arise from blood glucose and bind to serum proteins, and glycated albumin is produced when serum albumin is combined with glucose. Both of these measures have been shown to be elevated in the setting of hyperglycemia, and it is thought to be representative of the glycemic status for the past $2-3$ weeks [4]. In our patient, fructosamine was found to be elevated at $415 \mu \mathrm{mol}$ with a reference range of $210-421$ $\mu \mathrm{mol} / \mathrm{L}$. Glycated albumin in our patient was $4.7 \%$ with a reference range of $0.8-1.4 \%$. The fact that both of these levels are well above normal is indicative of a hyperglycemic state and poor diabetic control. Even though other markers have been explored for measuring glycemic control, there are several limitations to each measure. Since CLD-HbA1c has not been studied in patients with kidney failure, this comorbidity may limit the usage of CLD-HbAlc in this subgroup of patients. In addition, fructosamine and glycated albumin are both found to be affected in patients who have proteinuria or decreased albumin levels [4].

\section{Conclusion}

HbAlc by itself continues to be a valuable measure of glycemic control in T2DM and liver cirrhosis. However, in cases of patients with multiple comorbidities, its accuracy is diminished. In such patients health care providers must rely on other biomarkers. There is evidence to suggest that fructosamine and glycated albumin may be beneficial as part of normal monitoring in some cases of liver cirrhosis with discrepancy between HbA1c and blood glucose. However, these biomarkers can be inaccurate in patients with liver cirrhosis resulting in low albumin levels. Therefore, the best method for measuring glycemic status, in patients with T2DM and liver cirrhosis, is finger stick glucose monitoring.

\section{References}

1. Nathan DM, Kuenen J, Borg R, Zheng H, Schoenfeld D, Heine RJ. Translating the A1C assay into estimated average glucose values. Diabetes Care. 2008;31(8):14731478.

2. Hare MJ, Shaw JE, Zimmet PZ. Current controversies in the use of haemoglobin A1c. J Intern Med. 2012;271(3):227-236.

3 . Bonora E, Tuomilehto J. The pros and cons of diagnosing diabetes with A1C. Diabetes Care. 2011;34(Suppl 2):S184-190.

4. Blendea MC, Thompson MJ, Malkani S. Diabetes and Chronic Liver Disease: Etiology and Pitfalls in Monitor- 
ing. Clinical Diabetes. 2010;28(4):139-144.

5. Koga M, Kasayama S, Kanehara H, Bando Y. CLD (chronic liver diseases)-HbA1C as a suitable indica- tor for estimation of mean plasma glucose in patients with chronic liver diseases. Diabetes Res Clin Pract. 2008;81(2):258-262. 